\title{
Penerapan Metode Finite State Machine pada Pengembangan Game Edukasi Pengolahan Sampah
}

Ruziq Maulana*, Aries Suharso, Adhi Rizal

Program Studi Teknik Informatika, Fakultas IImu Komputer, Universitas Singaperbangsa Karawang, Indonesia

Email : ruziq.16201@student.unsika.ac.id*, aries.suharso@unsika.ac.id, adhi.riza@@staff.unsika.ac.id

Info Artikel

Kata Kunci :

game edukasi, MDLC, finite state machine, unity, pengolahan sampah

\section{Keywords :}

educational games, MDLC, finite state machine, unity, waste disposal

\section{Tanggal Artikel}

Dikirim : 10 April 2021

Direvisi : 30 APril 2021

Diterima : 30 Mei 2021

\begin{abstract}
Abstrak
Saat ini banyak orang yang tidak memiliki kesadaran akan kebersihan lingkungannya sendiri dan masih banyak yang membuang sampah sembarangan, yang akan menyebabkan pencemaran dan kerusakan lingkungan. Untuk meningkatkan kesadaran seseorang dalam hal sampah maka perlu adanya sebuah edukasi mengenai pengolahan sampah. Edukasi yang terbaik adalah edukasi yang dilakukan sejak dini, sehingga edukasi yang dilakukan akan tersimpan sampai tua nanti. Agar meningkatkan minat belajar anak-anak usia dini maka perlu adanya media yang menyenangkan bagi anak salah satunya menggunakan video game. Dalam pembuatan video game banyak metode yang dapat digunakan salah satunya adalah metode Finite State Machine. Tujuan dari penelitian ini iyalah bagaimana membuat game pengolahan sampah dengan menerapkan metode finite state machine dan mengukur tingkat penerimaan anak terhadap game yang dibuat. Metodologi yang digunakan dalam penelitian ini yaitu Multimedia Development Life Cycle (MDLC) dengan tools yang digunakan dalam membangun aplikasi yaitu Unity. Aplikasi ini berhasil memuat game pengolahan sampah dengan menerapkan metode Finite State Machine yang diimplementasikan pada NPC dan enemy. Implementasi uji coba aplikasi ini menggunakan pengujian usabilitas di mana hasil rata-rata yang didapatkan adalah $89,69 \%$.
\end{abstract}

\section{Abstarct}

Recently, many people do not have awareness of their own environmental cleanliness and still do littering that causes pollution \& environmental damage. To increase people awareness of waste problem, education of waste disposal need to be given. The best education is best given from early childhood so that the lesson will be remain until they are grown up. Fun media is needed to be given to improve children interest to learn, one of them is using video game. In making video game, many methods can be used, one of which is the Finite State Machine method. The purpose of this research is how to make a waste disposal video game by applying the finite state machine method and measuring the level of children's acceptance of the game. The methodology used in this research is the Multimedia Development Life Cycle (MDLC) with Unity as a tool to build the application. This application successfully loads the waste disposal game by applying the Finite State Machine method, which is implemented on NPCs and enemy. The trial implementation of the application uses a usability test where the average result obtained is $89.69 \%$. 


\section{PENDAHULUAN}

Di zaman yang segalanya serba instan kebersihan lingkungan hidup adalah sebuah hal yang penting. banyak masyarakat mulai memiliki sifat malas terutama malas dalam menjaga lingkungan sendiri dan menjaga kebersihan lingkungannya sendiri. Banyak sekali orang-orang membuang sampah di sembarang tempat, padahal tempat sampah ada di dekat orang-orang tesebut karena kurangnya kepedulian terhadap kebersihan lingkungannya dan masih banyak juga yang membuang limbah dan sampah di sungai-sungai yang akan terbawa ke laut dan akan mengotori laut dan membunuh bintang-bintang yang hidup di sungai ataupun laut, jika terjadi banjir, tanah longsor dan bencana lainnya yang disalahkan adalah pemerintahnya, bukannya mengintrospeksi diri padahal dirinya sendirilah yang tidak mau menjaga lingkungan disekitarnya. Indonesia adalah negara penghasil sampah terbanyak kedua setalah Cina [1] serta $72 \%$ masyarakat Indonesia mengenai masalah sampah masih kurang memiliki kepedulian data tersebut diambil dari Kementerian Lingkungan Hidup dan Kehutanan [2].

Data dari Kementerian Lingkungan Hidup dan Kehutanan tahun 2015 bahwa total sampah di Indonesia melebihi 187,2 juta ton per tahun [1] dan kalau setiap orang membuang sampah per hari sebesar $0,7 \mathrm{~kg}$ maka dapat di asumsikan bahwa sampah jumlah timbunan sampah nasional adalah sekitar 175 ribu ton per hari atau setara 64 juta ton per tahun [3]. Data dari Kementerian Lingkungan Hidup menyatakan bahwa jumlah sampah yang dibuang setiap harinya di tiap daerah di Indonesia rata-rata sebesar 300 - 600 ribu ton per hari [4]. Dilihat dari pemaparan tersebut jika setiap orang membuang sampah sembarangan tiap harinya maka lingkungan ini pada beberapa tahun akan semakin memburuk, virus dan bakteri akan mudah berkembang menyebabkan mudahnya penyakit menjangkit tiap manusia dan sampah-sampah tersebut akan ada selama berpuluh-puluh tahun karena sulitnya sampah terurai dan tidak ada pengolahan dan penanganan lebih lanjut. Jika lingkungan hidup ini tidak dijaga dari sekarang dalam hitungan tahun bumi ini bisa jadi sudah tidak lagi layak untuk dihuni oleh manusia. Solusi yang dapat digunakan untuk menyelesaikan masalah ini yaitu adalah memberikan edukasi sejak dini kepada anak-anak.

Anak-anak usia 4-6 tahun adalah masa di mana kepekaan seorang anak untuk menyerap sebuah informasi sangatlah baik karena segala sesuatu yang tertanam pada rentan usia ini akan terbawa hingga dewasa serta akan membentuk karakter dan kepribadian anak [5]. Maka umur 4-6 tahun adalah masa keemasannya diberikan pembelajaran mengenai pentingnya menjaga lingkungan hidupnya masing-masing. Penggunaan gadget tahun 2018 di Indonesia adalah sekiranya 177,9 juta jiwa dan pengguna terbanyak berasal dari anak-anak dan remaja. $80 \%$ orang tua memperbolehkan anaknya bermain gadget ditujukan untuk kebutuhan pembelajaran namun, kenyataannya $72 \%$ gadget yang digunakan oleh anak-anak malah untuk bermain game [6].

Game pada zaman sekarang mulai berkembang sangat pesat banyak orang-orang yang memainkan game untuk menghilangkan kejenuhannya selama beraktivitas atau hanya sekedar hiburan semata, namun game pada saat ini bisa dijadikan sebuah media pembelajaran yang menyenangkan bagi anak-anak seperti game belajar cara berhitung, mengenal huruf, belajar bahasa, simulasi dan masih banyak lagi. Metode edukasi menggunakan game memiliki kelebihan daripada menggunakan metode edukasi konvensional diantaranya adanya animasi dan terdapat gambar sehingga anak-anak dapat mengingat lebih banyak dan lebih lama dibandingkan dengan metode pembelajaran konvensional [7]. Banyak sekali metode yang dapat diterapkan dalam sebuah game salah satunya adalah metode Finite State Machine.

Finite State Machine adalah sebuah gambaran perhitungan menurut mesin hipotesis yang diciptakan dari beberapa kedudukan. Finite State Machine dipakai untuk memerintah dan menampilkan arus eksekusi yang berfungsi untuk menjalankan AI dalam permainan [8]. Metode finite state machine adalah metode yang lugas dan amat baik untuk memodelkan pribadi agen. Penerapan metode finite state machine pada agen diperuntukkan agar agen tampak bagai mengambil keputusan saat state pada agen tercatat terlaksanakan [8].

Penelitian mengenai game edukasi sebelumnya sudah pernah dilakukan diantaranya oleh [9], di mana peneliti membuat game pengenalan nama hewan dan habitatnya yang bertujuan untuk meningkatkan minat belajar, membantu perkembangan kecerdasan dan meningkatkan kemampuan anak dalam proses belajar anak-anak usia dini. Hasil dari penelitian ini menunjukkan bahwa gameyang dibuat efektif untuk membantu anak-anak dalam belajar. Penelitian yang dilakukan oleh Anik [7], membuat sebuah game yang ditujukan untuk media alternatif pembelajaran untuk mengenal simbol, berhitung, mencocokkan gambar dan menyusun acak kata. Hasil dari penelitian ini menunjukkan bahwa game yang dibuat dapat membantu guru dan siswa PAUD dalam mengubah cara belajar konvensional menjadi cara belajar simulasi dengan media game [7].

Dari hasil pemaparan di atas peneliti ingin membuat sebuah game pengolahan sampah dengan menerapkan metode finite state machine dan mengukur tingkat penerimaan peserta didik terhadap game edukasi pengolahan 
sampah ini. Beberapa batasan dalam penelitian ini iyalah game dibuat hanya bisa dimainkan oleh satu orang saja, game yang dibuat akan berjalan di platform desktop, game ini dikhususkan untuk anak-anak TK/PAUD, game akan dibuat menggunakan tools Unity, game yang dibuat bersifat 2 dimensi (2D), dan tidak membahas pengaruh game yang dibuat terhadap psikologi anak.

\section{METODE PENELITIAN}

Objek penelitian yang akan diteliti adalah game edukasi pengolahan sampah dengan menerapkan metode finite state machine. Adapun tempat penelitian akan dilakukan di TK Al-Manshurin Bandung.

Tahapan-Tahapan Rancangan Penelitian yang dilakukan pada penelitian ini yaitu menggunakan tahapan-tahapan yang sesuai dengan metode Multimedia Development Life Cycle. Alur dari rancangan penelitian digambarkan sebagai berikut :

(1) Concept, tahap menentukan tujuan yaitu membuat sebuah game pengolahan sampah dengan menggunakan metode finite state machine untuk anak-anak TK di mana diharapkan dengan game ini anak-anak dapat lebih mudah memahami mengenai masalah sampah dan bagaimana cara pengolahannya, serta menentukan pengguna yaitu anakanak sebagai pengguna langsung dan guru sebagai pendamping.

(2) Design, tahap pembuatan spesifikasi mengenai tampilan, penyusunan alur flowchart sebagai gambaran alur cerita game seperti apa, pembuatan storyboard untuk memberikan gambaran dari setiap scene pada game, dan kebutuhan material.

(3) Material Colleting, tahap pengumpulan bahan-bahan yang sesuai dengan kebutuhan. Bahan-bahan yang dibutuhkan antara lain gambar sebagai tampilan game, dan audio untuk memberikan suara pada alur cerita.

(4) Assembly, tahap penerapan metode finite state machine pada NPC (Non Playable Character) dan enemy. Pada tahap ini juga tahap di mana dilakukan pembuatan dan pengkodean menggunakan aplikasi Unity di mana aset-aset yang telah dibuat, dikumpulkan dan dikombinasikan. hingga game dapat dijalankan dengan baik.

(5) Testing, tahapan pengujian dengan melakukan pengujian alpha test yaitu pengujian yang dilakukan oleh pembuat atau lingkungan pembuatnya sendiri, jika terjadi bug atau kesalahan akan dilakukan evaluasi dan perbaikan kemudian dilakukan pengujian kembali hingga game berjalan dengan baik yaitu menggunakan pengujian fungsionalitas. Pada tahap ini juga dilakukan pengujian pada metode finite state machine di mana pengujian disesuaikan dengan di mana finite state machine diterapkan yaitu pada NPC dan Enemy. kemudian dilakukan pengujian beta test yaitu pengujian yang melibatkan pengguna akhir yaitu anak-anak TK di mana pengujian ini dilakukan menggunakan pengujian usabilitas untuk mengetahui apakah game pengolahan sampah ini dapat memberikan edukasi kepada anak-anak. Untuk mengetahui hal tersebut setelah anak-anak mencoba memainkan game pengolahan sampah akan dilakukan metode wawancara kepada anak-anak menggunakan kuesioner.

(6) Distribution, tahapan pendistribusian game ke taman kanak-kanak untuk dipergunakan sebagai media pembelajaran kedepannya.

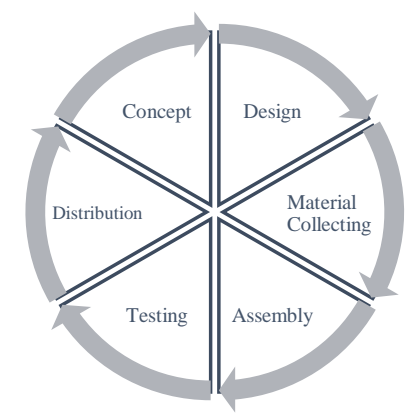

Gambar 1. Rancangan Penelitian

\section{HASIL DAN PEMBAHASAN}

\subsection{Konsep}

Pada tahap ini merupakan tahapan untuk mencari kebutuhan informasi yang dibutuhkan, terdapat beberapa tahapan dalam menentukan konsep game edukasi pengolahan sampah ini di antaranya:

(1) Identifikasi Pengguna 
Gambar diberi nomor urut dan keterangan lengkap, dan harus diacu dalam tulisan. Keterangan pada gambar ditulis di bawah gambar, dengan huruf kecil kecuali pada karakter pertama pada tiap kalimat. Posisi gambar dan keterangan gambar diletakkan di tengah (rata-tengah). Pada gambar yang diambil dari referensi lain dicantumkan sumber pustakanya.

Pada tahap ini dilakukan identifikasi siapa saja target pengguna game edukasi ini, yaitu terdiri dari:

1. Pengajar sebagai pembimbing dan pengawas anak-anak dalam memainkan game ini.

2. Anak-anak sebagai pengguna game secara langsung.

(2) Identifikasi Perangkat

Pada tahap ini dilakukan identifikasi game yang dibuat akan berjalan yang mana akan berjalan di platform desktop (Personal Computer/Laptop) dan mengidentifikasi software dan hardware yang akan digunakan diantaranya:

1. Adobe lllustrator digunakan untuk mendesain konsep game serta assetyang dibutuhkan dalam game.

2. RPG Character Builder digunakan untuk mendesain karakter dalam game.

3. Unity digunakan untuk menyatukan asset-asset serta mengembangkan game.

4. Spesifikasi hardware yang digunakan yaitu laptop HP dengan Processor AMD Ryzen $33200 \mathrm{U}$ with Radeon Vega Mobile Gfx 260 Ghz, 4 GB RAM dan HDD 100 GB.

\subsection{Desain}

Tahapan ini merupakan tahapan untuk mendesain game yang akan dikembangkan. Tahap desain meliputi desain storyboard. Untuk Gambaran story board dapat dilihat pada Gambar 2, kemudian untuk penjelasan tiap scene pada storyboard dapat dilihat dibawah ini:

(1) Menampilkan menu utama terdiri dari dua tombol yaitu tombol mulai dan tombol cara bermain.

(2) Menampilkan menu cara bermain.

(3) Menampilkan menu pilih karakter yang terdiri dari karakter perempuan dan karakter laki-laki.

(4) Menampilkan level satu dengan latar tempat pantai.

(5) Menampilkan leve/ dua dengan latar tempat taman.

(6) Menampilkan leveltiga dengan latar tempat jalan atau kota.

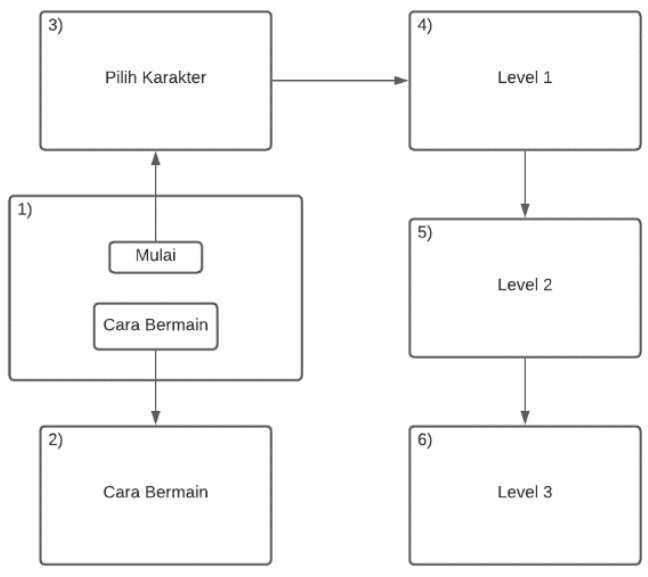

Gambar 2. Storyboard Aplikasi

\subsection{Pembuatan}

Setelah bahan-bahan yang dibutuhkan telah dikumpulkan langkah selanjutnya adalah memulai untuk membuat game edukasi pengolahan sampah pada aplikasi Unity.

\subsubsection{Pembuatan desain interface game menu utama}

Menu utama ini adalah tampilan awal saat game dimainkan. Tampilan menu terdiri dari tombol mulai, cara bermain, dan exit seperti yang dapat dilihat pada Gambar 3. cara bermain, dan exit seperti yang dapat dilihat pada Gambar 3. 


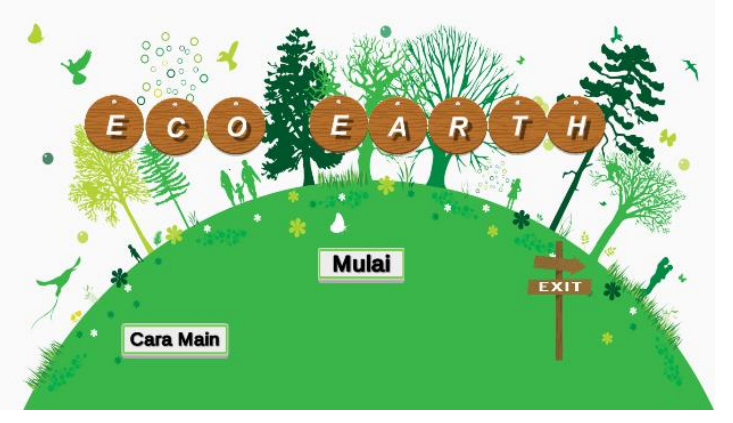

Gambar 3. Desain Menu Utama

\subsubsection{Pembuatan desain interface cara bermain}

Ketika pemain menekan tombol cara bermain maka menu cara bermain akan muncul di mana menu ini diperuntukan untuk mengetahui dan mempelajari bagaimana cara untuk bermain dan tujuan yang harus dicapai. Untuk tampilan menu cara bermain dapat dilihat pada Gambar 4.

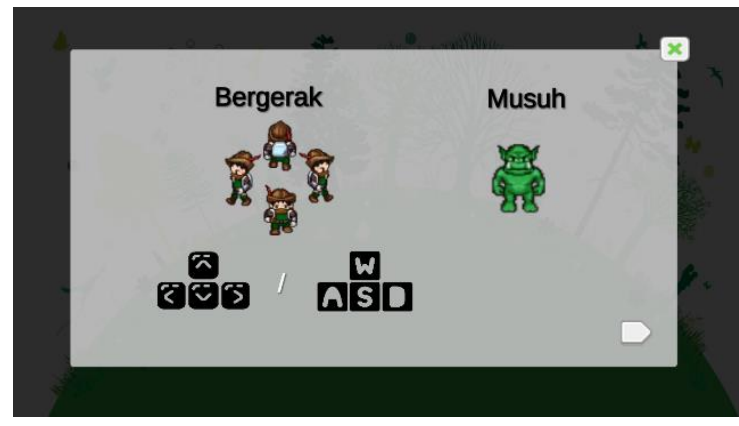

Gambar 4. Desain Cara Main

\subsubsection{Pembuatan Desain Interface Pilih Karakter}

Saat pemain menekan tombol mulai maka akan muncul menu pilih karakter di mana pemain bisa memilih karakter antara karakter laki-laki atau karakter perempuan. Tampilan menu pilih karakter dapat dilihat pada Gambar 5.

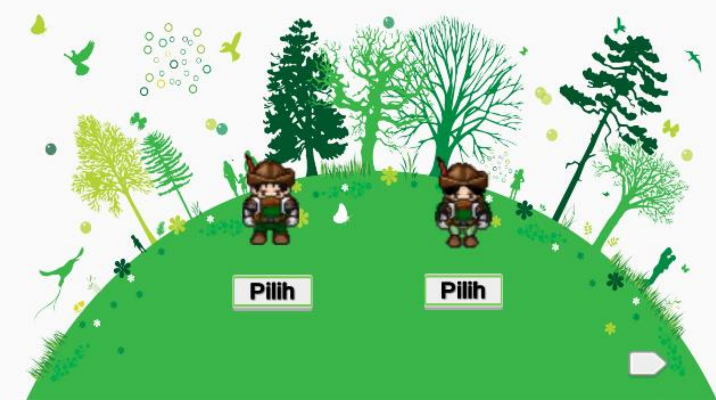

Gambar 5. Desain Pilih Karakter

\subsubsection{Pembuatan desain interface level}

Saat pemain telah memilih karakter yang akan digunakan, selanjutnya permainan akan dimulai pada leve/satu. Pada level satu ini tema tempat yang diambil adalah pantai dengan sampah yang dapat dipungut adalah sampah 
plastik dengan score tiap sampahnya adalah 100 dan sampah botol dengan score tiap sampahnya adalah 200. Pada level ini NPC (Non Playable Character) yang terdapat pada level ini terdapat satu NPC dan menjatuhkan sampah plastik dan botol secara random dan enemy pada level ini terdapat satu enemy.

Setelah pemain berhasil melewati level satu maka pemain akan melanjutkan permainan pada level dua. Pada level ini tema tempat yang diambil adalah taman, sampah yang dapat diambil ada lima macam yaitu sampah plastik dengan score 100, sampah botol dengan score 200 , sampah kertas dengan score 300 , sampah kaleng dengan score 400, dan sampah basah dengan score 500. NPC yang terdapat pada level ini ada dua NPC, NPC perempuan akan menjatuhkan sampah plastik dan sampah botol sedangkan NPC laki-laki akan menjatuhkan sampah kertas, kaleng, dan sampah basah. Enemy yang terdapat dalam level ini terdapat dua enemy.

Setelah pemain dapat bertahan dan menyelesaikan level satu dan dua selanjutnya pemain akan memasuki leve/tiga. Pada levelini tema tempat yang diambil adalah perkotaan atau jalan. Sampah yang dapat diambil, dan NPC pada level ini sama dengan leveldua yang membedakan adalah enemy pada levelini terdapat tiga enemy. Gambaran tampilan leve/ dapat dilihat pada Gambar 6.

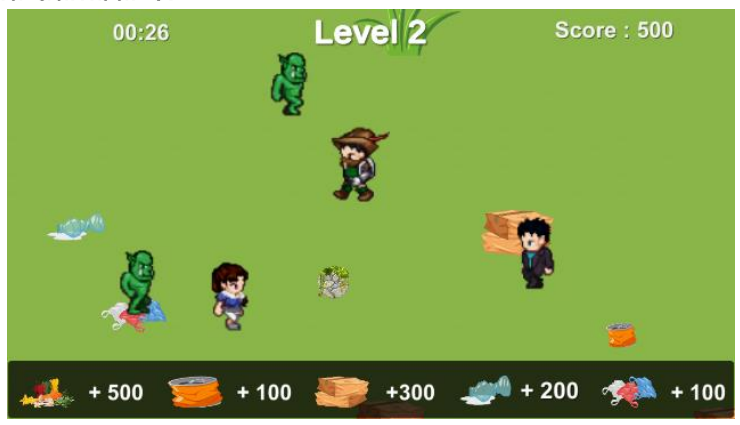

\section{Gambar 6. Desain Game}

\subsubsection{Penerapan metode Finite State Machine pada game}

Metode finite machine yang digunakan pada game pengolahan sampah ini diterapkan untuk mengatur tingkah laku NPC dan enemy dan respons apa yang harus dilakukan.

Untuk penerapan finite state machine pada NPC, state yang diterapkan dalam mengatur tingkah laku NPC (Non Playable Character) menggunakan dua state yaitu wander dan flee. State default pada tingkah laku NPC adalah wandering di mana pada state ini NPC akan bergerak secara random. Agar state berpindah dari wander ke state flee maka jarak antara NPC dengan player haruslah sama dengan 4. Pada state flee NPC akan bergerak menjauhi player sampai jarak NPC dengan player sama dengan 7 , kemudian state akan berpindah kembali pada state wander. Gambaran finite state machine yang diterapkan pada NPC dapat dilihat pada Gambar 7.

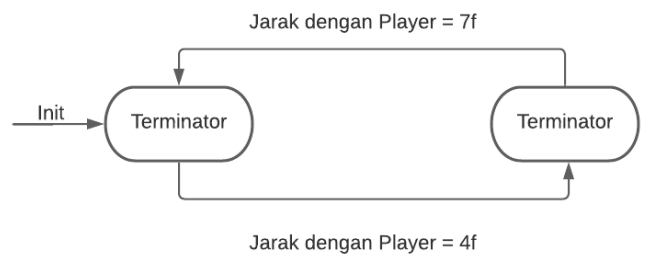

\section{Gambar 7. Penerapan Finite State Machine pada NPC}

Untuk penerapan finite state machine pada enemy, state yang diterapkan dalam mengatur tingkah laku enemy menggunakan tiga state yaitu patrol, chase, dan attack. State default pada tingkah laku enemy adalah patrol di mana pada state ini enemy akan bergerak secara random. Agar state berpindah dari patrolke state chase maka jarak antara enemy dengan player haruslah sama dengan 7. Pada state chase enemy akan mengejar player sampai jarak antara player dengan enemy adalah 4. Saat jarak antara player dengan enemy adalah 4 maka state akan berpindah ke state attack dan enemy akan menyerang player dengan cara melemparkan batu pada player. Kemudian jika jarak enemy dengan player sama dengan 9 maka enemy akan kembali pada state patrol dan kembali bergerak secara random. Gambaran finite state machine yang diterapkan pada enemy dapat dilihat pada Gambar 8. 


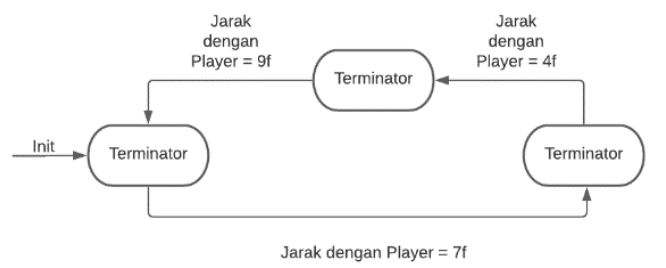

Gambar 8. Penerapan Finite State Machine pada Enemy

\subsubsection{Pembuatan scene didalam game}

Dalam pembuatan game seluruh bahan-bahan yang telah dikumpulkan kemudian dibuat menjadi satu kesatuan dalam tools Unity serta memberikan kode-kode untuk menjalankan setiap fungsi-fungsi tombol, mengontrol animasi, dan mengontrol scene. Langkah awal yang harus dilakukan adalah membuat project, setelah itu membuat masing-masing scene yang dibutuhkan dalam game yang dibuat. Kemudian pada tiap scene ditambahkan object yang dibutuhkan dan memberikan kode-kode pada setiap object untuk mengatur fungsi object.

Pada pembuatan scene menu ada beberapa menu yang dibuat yaitu menu awal, cara bermain, dan menu pilih karakter. Untuk kode-kode diberikan pada tiap tombol-tombol untuk mengatur, membuka menu cara bermain, pilih karakter, mulai game, dan tombol quit game. Pembuatan main menu dapat dilihat pada Gambar 9.

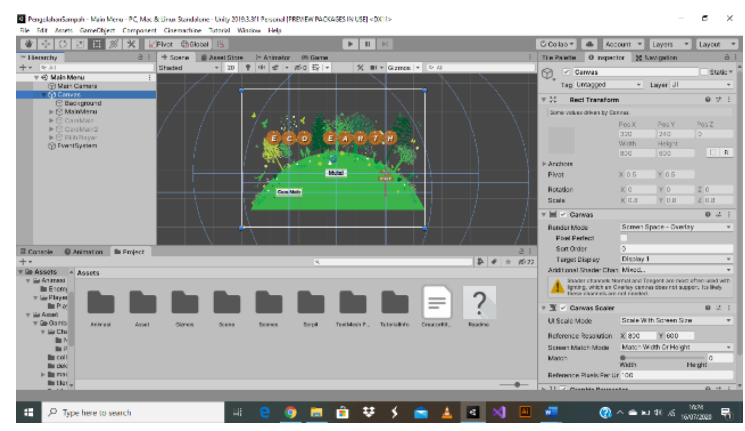

\section{Gambar 9. Pembuatan Scene Menu}

Pada pembuatan scene level game objectyang dimasukan adalah player, enemy, NPC, sampah, menu score, menu pause, win menu, lose menu, dekorasi, grid digunakan sebagai tilemap dan pembatas, dan waypoint sebagai point bergerak enemy dan NPC. Kemudian kode-kode diberikan pada setiap object sebagai pengatur fungsi tiap object dan mengatur jalannya permainan. Pembuatan scene level dapat dilihat pada Gambar 10.

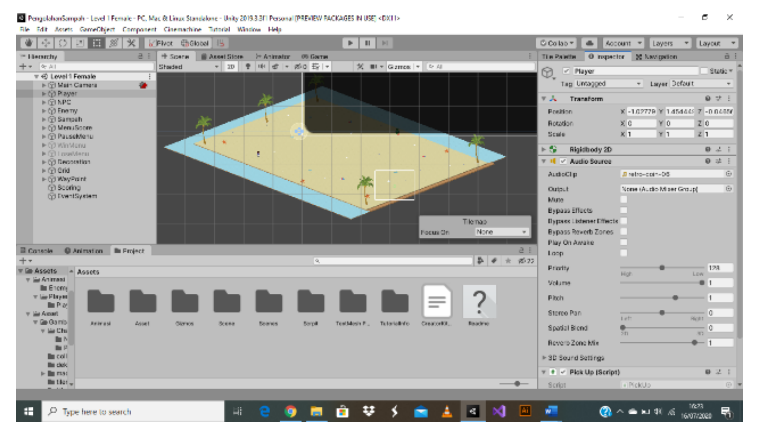

Gambar 10. Pembuatan Scene Level 


\subsubsection{Export game ke dalam format .exe}

Setelah semua aspek-aspek dalam game telah selesai, selanjutnya adalah memasukan semua scene dan menyatukan ke dalam builder, kemudian pilih platform yang ingin di export lalu klik build dan game akan dibuat menjadi bentuk .exe dan game siap dimainkan. Tampilan untuk export game dapat dilihat pada Gambar 11.

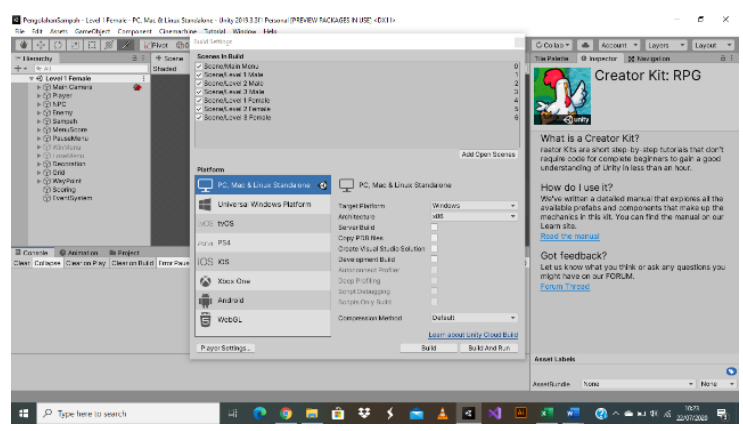

Gambar 11. Export Game

\subsection{Pengujian}

Pada tahap ini dilakukan dua pengujian yang pertama adalah pengujian Alpha yang bertujuan untuk menguji fungsional dan metode finite state machine dari aplikasi, kemudian pengujian Beta untuk menguji tingkat penerimaan anak-anak terhadap aplikasi.

\subsubsection{Pengujian Alpha}

Pengujian Alpha dilakukan untuk mengetahui apakah ada kesalahan pada fungsional perangkat lunak, apakah perangkat lunak telah berjalan sesuai dengan apa yang diharapkan. Pengujian ini juga dilakukan untuk mengetahui apakah metode yang diterapkan berjalan sesuai dengan apa yang diharapkan. Pada pengujian ini menggunakan angket dengan skala Guttman sebagai bentuk penilaian game terhadap instrumen pengujian.

Pengujian pertama adalah pengujian fungsional. Pengujian ini dilakukan oleh penulis dengan menguji semua elemen beserta fungsinya yang terdapat didalam game edukasi ini. Pengujian dilakukan agar mengetahui apakah hasil yang diinginkan sesuai dengan yang diharapkan atau tidak, selain itu pengujian ini juga bertujuan untuk mencari kemungkinan kesalahan yang terjadi dalam setiap proses. Table hasil pengujian dapat dilihat pada Tabel 1.

\section{Tabel 1. Hasil Pengujian Fungsional}

\begin{tabular}{clcc}
\hline No & \multicolumn{1}{c}{ Aspek } & Total Skor & Persentase \\
\hline 1 & Pengujian Menu Utama & 3 & $100 \%$ \\
\hline 2 & Pengujian Menu Cara Bermain & 3 & $100 \%$ \\
\hline 3 & Pengujian Menu Pilih Karakter & 3 & $100 \%$ \\
\hline 4 & Pengujian Menu Pause & 4 & $100 \%$ \\
\hline 5 & Pengujian Menu Win Level 1 & 3 & $100 \%$ \\
\hline 6 & Pengujian Menu Win Level 2 & 3 & $100 \%$ \\
\hline 7 & Pengujian Menu Win Level 3 & 3 & $100 \%$ \\
\hline 8 & Pengujian Menu Lose & 3 & $100 \%$ \\
\hline 9 & Pengujian Player & 4 & $100 \%$ \\
\hline \multicolumn{2}{c}{ Total } & 29 & $100 \%$ \\
\hline
\end{tabular}

Hasil dari pengujian fungsional yang telah dilakukan membuktikan bahwa tidak ada kesalahan dan fungsifungsinya sudah berjalan dengan baik serta hasil telah sesuai dengan yang diharapkan.

Pengujian kedua adalah pengujian penerapan metode finite state machine. Pengujian ini dilakukan untuk mengetahui apakah metode yang diterapkan sudah berjalan dengan baik atau belum dan sesuai dengan yang diharapkan. Metode finite state machine ini diterapkan pada enemy dan NPC (Non Playable Character). Untuk pengujian finite state machine dapat dilihat pada Tabel 2 dan Tabel 3. 
Tabel 2. Pengujian Finite State Machine pada Enemy

\begin{tabular}{ccccc}
\hline No & Aksi / Event & State & $\begin{array}{c}\text { Hasil yang } \\
\text { diharapkan }\end{array}$ & Skor \\
\hline 1 & State Awal / Default & Patrol & $\begin{array}{c}\text { Bergerak secara } \\
\text { random }\end{array}$ & 1 \\
\hline 2 & $\begin{array}{c}\text { Jarak antara enemy dan Player } \\
=7 f\end{array}$ & Chase & $\begin{array}{c}\text { Bergerak mengejar } \\
\text { player }\end{array}$ & 2 \\
\hline 3 & $\begin{array}{c}\text { Jarak antara enemy dan Player } \\
=4 f\end{array}$ & Attack & Menyerang player & 3 \\
\hline 4 & $\begin{array}{c}\text { Jarak antara enemy dan Player } \\
=9 f\end{array}$ & Patrol & $\begin{array}{c}\text { Kembali bergerak } \\
\text { secara random }\end{array}$ & 4 \\
\hline \multicolumn{2}{c}{ Total } \\
\hline \multicolumn{3}{c}{ Persentase } \\
\hline
\end{tabular}

Tabel 3. Pengujian Finite State Machine pada NPC

\begin{tabular}{ccccc}
\hline No & Aksi / Event & State & $\begin{array}{c}\text { Hasil yang } \\
\text { diharapkan }\end{array}$ & Skor \\
\hline $\mathbf{1}$ & State Awal / Default & Wandering & $\begin{array}{c}\text { Bergerak secara } \\
\text { random }\end{array}$ & 1 \\
\hline $\mathbf{2}$ & Jarak antara NPC dan Player $=4 \mathrm{f}$ & Flee & $\begin{array}{c}\text { Bergerak menjauhi } \\
\text { player }\end{array}$ & 1 \\
\hline $\mathbf{3}$ & Jarak antara NPC dan Player $=7 f$ & Wandering & $\begin{array}{c}\text { Bergerak secara } \\
\text { random kembali }\end{array}$ & 1 \\
\hline \multicolumn{7}{c}{ Total } & & 3 \\
\hline Persentase & $100 \%$ \\
\hline
\end{tabular}

Hasil dari pengujian yang telah dilakukan menghasilkan bahwa metode finite state machine yang diterapkan pada enemy dan NPC berjalan dengan baik dan tidak ditemukan masalah yang terjadi.

\subsubsection{Pengujian beta}

Pengujian beta dilakukan untuk mengetahui sejauh mana tingkat penerimaan peserta didik terhadap game yang telah dibuat. Pengujian ini dilakukan kepada 22 anak di TK Al-Manshurin Bandung, anak-anak diminta untuk menggunakan game yang telah dibuat. Pada pengujian ini menggunakan angket dengan skala Likert sebagai bentuk penilaian game terhadap instrument pengujian

Langkah awal yang harus dilakukan mengetahui berapa tingkat penerimaan peserta didik terhadap gameyang telah dibuat adalah menentukan interval dan interpretasi persen agar mengetahui penilaian dengan metode mencari interval skor persen (I). pilihan angka skor likert yang digunakan adalah:

(1) Sangat Setuju $=5$.

(2) Setuju $=4$.

(3) Netral $=3$.

(4) Tidak Setuju $=2$.

(5) Sangat Tidak Setuju $=1$.

Kemudian yang harus dilakukan adalah mencari interval yaitu dengan rumus:

$I=100 /$ jumlah skor.

$I=100 / 5=20$.

Maka jarak intervalnya adalah 20\%, sehingga didapatkan hasil interval penilaian seperti pada Tabel 4 .

Tabel 4. Interval Penilaian

\begin{tabular}{cc}
\hline Interval & Keterangan \\
\hline $0 \%-19,99 \%$ & Sangat Setuju \\
\hline $20 \%-39,99 \%$ & Setuju \\
\hline $40 \%-59,99 \%$ & Netral \\
\hline $60 \%-79,99 \%$ & Tidak Setuju \\
\hline $80 \%-100 \%$ & Sangat Tidak Setuju \\
\hline
\end{tabular}


Langkah selanjutnya adalah menghitung jumlah hasil pengujian tiap pertanyaan yang dapat dilihat pada Tabel 5 .

Tabel 5. Hasil Pengujian

\begin{tabular}{ccccccc}
\hline Responden & $\mathbf{X 1}$ & $\mathbf{X 2}$ & $\mathbf{X 3}$ & $\mathbf{X 4}$ & $\mathbf{X 5}$ & $\mathbf{X 6}$ \\
\hline 1 & 4 & 4 & 5 & 5 & 5 & 5 \\
\hline 2 & 4 & 4 & 5 & 5 & 5 & 5 \\
\hline 3 & 4 & 4 & 5 & 5 & 5 & 5 \\
\hline 4 & 4 & 4 & 5 & 5 & 5 & 5 \\
\hline 5 & 5 & 5 & 5 & 5 & 5 & 5 \\
\hline 6 & 4 & 4 & 5 & 5 & 5 & 5 \\
\hline 7 & 5 & 5 & 5 & 5 & 5 & 5 \\
\hline 8 & 4 & 4 & 5 & 5 & 5 & 5 \\
\hline 9 & 4 & 4 & 3 & 4 & 5 & 5 \\
\hline 10 & 4 & 4 & 4 & 4 & 4 & 4 \\
\hline 11 & 4 & 4 & 4 & 4 & 5 & 5 \\
\hline 12 & 4 & 4 & 5 & 5 & 5 & 5 \\
\hline 13 & 4 & 4 & 4 & 4 & 5 & 4 \\
\hline 14 & 5 & 5 & 5 & 4 & 5 & 5 \\
\hline 15 & 4 & 4 & 5 & 4 & 5 & 5 \\
\hline 16 & 5 & 5 & 4 & 5 & 5 & 5 \\
\hline 17 & 4 & 4 & 5 & 4 & 5 & 5 \\
\hline 18 & 4 & 4 & 3 & 3 & 3 & 5 \\
\hline 19 & 4 & 3 & 3 & 3 & 3 & 3 \\
\hline
\end{tabular}

Lalu selanjutnya adalah mencari hasil interpretasi dengan cara mencari skor tertinggi $(\mathrm{Y})$ dan skor terendah $(\mathrm{X})$ dengan rumus sebagai berikut:

$Y=$ skor tertinggi $x$ jumlah responden.

$Y=5 \times 22=110$.

$X=$ skor terendah $x$ jumlah responden.

$X=1 \times 22=22$.

Kemudian mencari indeks persen (\%) tiap pertanyaan dengan rumus:

Indeks $(\%)=$ total skor $/ Y \times 100$.

Maka didapat hasil nilai usabilitas seperti pada Tabel 6 .

Tabel 6. Rekap Nilai Usabilitas

\begin{tabular}{clcc}
\hline No & \multicolumn{1}{c}{ Pertanyaan } & Peesentase & Keterangan \\
\hline 1 & Aplikasi game mudah dioperasikan & $85,45 \%$ & Sangat Setuju \\
\hline 2 & $\begin{array}{l}\text { Mudah menggerakkan karakter } \\
\text { pemain }\end{array}$ & $84,54 \%$ & Sangat Setuju \\
\hline 3 & Tampilan game menarik & $90 \%$ & Sangat Setuju \\
\hline 4 & $\begin{array}{l}\text { Simbol-Simbol gambar mudah } \\
\text { dipahami }\end{array}$ & $88,18 \%$ & Sangat Setuju \\
\hline 5 & $\begin{array}{l}\text { Mudah mengingat jenis-jenis sampah } \\
\text { pada game }\end{array}$ & $94,54 \%$ & Sangat Setuju \\
\hline 6 & $\begin{array}{l}\text { Mudah memahami tujuan yang harus } \\
\text { dicapai dalam game }\end{array}$ & $95,45 \%$ & Sangat Setuju \\
\hline \multicolumn{2}{c}{ Rata-rata } & $89,69 \%$ & Sangat Setuju \\
\hline
\end{tabular}

Dari Tabel 6 dapat dilihat bahwa rata-rata tingkat anak-anak didik di TK Al-Manshurin Bandung terhadap game pengolahan sampah adalah $89,69 \%$ yang berarti anak-anak sangat menerima game pengolahan sampah ini. 


\section{KESIMPULAN}

Berdasarkan penelitian yang telah dilakukan maka terdapat beberapa kesimpulan yang dapat diambil yaitu:

(1) Penelitian ini berhasil membuat game edukasi dengan menerapkan metode finite state machine pada NPC dan enemy serta menghasilkan respons NPC dan enemy yang baik pada pemain dan berjalan dengan sebagaimana mestinya.

(2) Berdasarkan hasil pengujian yang telah dilakukan tingkat penerimaan peserta didik terhadap game pengolahan sampah ini memiliki rata-rata $89,69 \%$ yang di mana dalam interval penilaian peserta didik "Sangat Setuju" terhadap game pengolahan sampah ini.

\section{DAFTAR PUSTAKA}

[1] P. Purwaningrum, "Upaya Mengurangi Timbulan Sampah Plastik Di Lingkungan,” Indones. J. Urban Environ. Technol., vol. 8, no. 2, p. 141, 2016, doi: 10.25105/urbanenvirotech.v8i2.1421.

[2] Din, "KLHK: 72 Persen Masyarakat Tak Peduli dengan Sampah Plastik," CNN Indonesia, Jakarta, Aug. 21, 2019.

[3] N. F. A. B. Baqiroh, "Timbulan Sampah Nasional Capai 64 juta ton per Tahun," Bisnis.com, Jakarta, Feb. 21, 2019.

[4] N. Sari and S. A. Mulasari, "Pengetahuan, Sikap Dan Pendidikan Dengan Perilaku Pengelolaan Sampah Di Kelurahan Bener Kecamatan Tegalrejo Yogyakarta," J. Med. Respati, vol. 12, no. April, pp. 1907-3887, 2017, [Online]. Available: http://eprints.uad.ac.id/8012/1/30-55-1-SM.pdf.

[5] F. Chandra, A. Dektisa, and B. D. Arini, "Perancangan Permainan Interaktif Sebagai Pendukung Optimalisasi Golden Age Pada Anak," J. DKV Adiwarna, vol. Vol 1, no. No 12, 2018, [Online]. Available: http://publication.petra.ac.id/index.php/dkv/article/view/7102.

[6] M. Zaini and S. Soenarto, "Persepsi Orangtua Terhadap Hadirnya Era Teknologi Digital di Kalangan Anak Usia Dini," J. Obs. J. Pendidik. Anak Usia Dini, vol. 3, no. 1, p. 254, 2019, doi: 10.31004/obsesi.v3i1.127.

7] A. V. Vitianingsih, "Game Edukasi Sebagai Media Pembelajaran Pendidikan Anak Usia Dini," Inf. J. IIm. Bid. Teknol. Inf. dan Komun., vol. 1, no. 1, pp. 25-32, 2016, [Online]. Available: https://ejournal.unitomo.ac.id/index.php/inform/article/view/220.

[8] E. Yulsilviana and H. Ekawati, "Penerapan Metode Finite State Machine (Fsm) Pada Game Agent Legenda Anak Borneo," pp. 116-123, 2019.

[9] R. A. Rahman and D. Tresnawati, "Pengembangan Game Edukasi Pengenalan Nama Hewan dan Habitatnya Dalam 3 Bahasa Sebagai Media Pembelajaran Berbasis Multimedia," J. Algoritm., vol. 13, no. 1, pp. 184190, 2016, doi: 10.33364/algoritma/v.13-1.184 